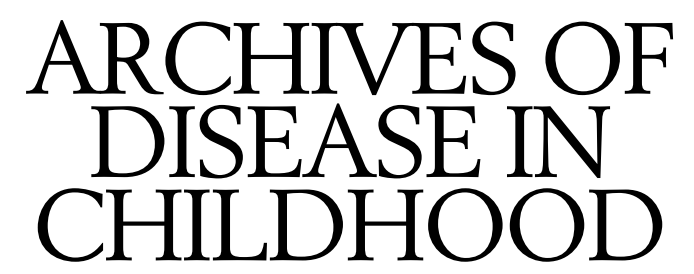

The Fournal of the Royal College of Paediatrics and Child Health

\title{
Annotations
}

\section{The risks and benefits of cisapride in premature neonates, infants, and children}

The Medicines Control Agency and the Committee on Safety of Medicines (CSM) recently stated that cisapride is contraindicated in infants born before 36 weeks' gestation for three months after birth, and that there is insufficient data to support the use of cisapride in children up to 12 years of age. ${ }^{1}$ These statements need qualification. Many believe cisapride to be a safe and useful agent in a variety of intestinal motility disorders especially in premature infants. Furthermore, data seem to support the use of cisapride throughout childhood.

The only support the CSM referenced for their first statement was a study showing clinically asymptomatic electrocardiographic increases in the QTc interval to $>450$ in seven of 49 neonates, six of whom were born $\leqslant 33$ weeks' gestation. ${ }^{2}$ This gives reason for caution but not contraindication.

Concern relates to QTc > 450, which may predispose to arrhythmias and are a risk factor for sudden infant death (SID). ${ }^{3}$ Increases in QTc and arrhythmias are more noticeable with high doses of cisapride ${ }^{4}$ and when cisapride inactivation is impaired by drugs acting via the cytochrome P450 3A4 system, ${ }^{5}$ such as macrolide antibiotics (erythromycin, clarithromycin) and azole antifungals (fluconazole, itraconazole, ketoconazole or miconazole). But with care is cisapride dangerous? Hill and colleagues ${ }^{6}$ found the mean (SD) QTc in 35 children on cisapride to be 428 (35) with QTc > 450 in 11 children. However, only two had torsades de pointes and both were taking a macrolide antibiotic. Lupoglazoff and colleagues ${ }^{7}$ reported seven cases of asymptomatic QTc prolongation with a mean of 486 (450-540) but dosage was high at $1-1.7 \mathrm{mg} / \mathrm{kg} /$ day; Levine et al found no change in QTc in children taking $0.8 \mathrm{mg} / \mathrm{kg} /$ day. ${ }^{8}$ However, we have found that in 17 surgical neonates mean (SD) QTc rose from 373 (31) to 389 (19) $(\mathrm{p}=0.03)$ while taking cisapride $0.6 \mathrm{mg} / \mathrm{kg} /$ day orally or $2 \mathrm{mg} / \mathrm{kg} /$ day rectally (bioavailabilty $=40 \%,{ }^{9}$ ) but in no patient did the QTc exceed 450 after starting cisapride.

In one study of 20 ventilated premature neonates the mean gastric residue after feeds decreased on cisapride and the mean feeding volume increased. ${ }^{10}$ Cisapride also reduced the time to the first sustained feed and increased the mean daily net enteral balance in neonates with a prolonged ileus after abdominal surgery. ${ }^{11}$

A working group of the European Society of Paediatric Gastroenterology and Nutrition recommended that prokinetic agents such as cisapride have a place in the treatment of gastro-oesophageal reflux (GOR) especially if positional and dietary recommendations fail. ${ }^{12}$ Cisapride increases lower oesophageal sphincter pressure and the amplitude and duration of peristaltic waves. ${ }^{13}$ Cisapride reduces oesophageal acid exposure, the duration of reflux episodes, the duration of the longest episode, and the number of long lasting episodes. ${ }^{13-18}$ Many of these studies are randomised, double blind, placebo controlled trials. Symptom improvement with cisapride treatment is greater than after postural and dietary treatment alone, ${ }^{13}$ and in one study nocturnal cough disappeared completely in 12 of 13 children taking cisapride. ${ }^{16}$ In a placebo controlled trial in 137 infants less than 1 year of age with severe GOR, cisapride significantly reduced the frequency and severity of regurgitation. ${ }^{19}$ In a double blind, placebo controlled trial in 20 children (aged 75 days to 47 months) with GOR and peptic oesophagitis there was significant histological improvement only in those treated with cisapride. ${ }^{20}$ Cisapride is also more effective than metoclopramide ${ }^{21}$ and is useful in children with cystic fibrosis and GOR. ${ }^{22} 23$

In 10 children with encopresis unresponsive to vigorous treatment, symptoms ceased in eight and improved in the other two. ${ }^{24}$ In another trial cisapride increased stool frequency from a mean (SD) of $1.4(0.5)$ to 6.5 (4.2) stools/week $(\mathrm{p}<0.05)$ and accidents decreased from 2.9 (2.7) to $0.5(1.2)(\mathrm{p}<0.05)$ with encopresis disappearing in $65 \%$ of cases and improving in $26 \% .^{25}$ Two further double blind, placebo controlled trials showed cisapride to improve bowel habits in children with chronic idiopathic constipation. ${ }^{26}{ }^{27}$ Stool frequency was increased from 1.2 $(0.6)$ to 5.1 (1.9) stools/week ( $<<0.05)$, and transit time was decreased from 91 (9) hours to 57 (20) hours $(\mathrm{p}<0.05)$.

Cisparide is useful in children with chronic intestinal pseudo-obstruction ${ }^{28}$ with those having migrating motor complexes responding best, ${ }^{29}$ especially if there is postprandial duodenal hypomotility. ${ }^{30}$ A prospective, randomised, controlled study in children after uncomplicated heart surgery found cisapride reduced intestinal transit time. ${ }^{31}$

We believe that the case against cisapride as a safe and extremely useful agent in premature neonates and throughout childhood has not been satisfactorily expounded by the CSM. Our practice is to prescribe oral cisapride at $0.6-0.8 \mathrm{mg} / \mathrm{kg} /$ day, measuring QTc before and after starting treatment. We accept that cisapride should not be used when the QTc is $>450$ or with contraindicated drugs, but we are keen that the CSM should revisit the question of prematurity.

ANTHONY LANDER

Senior Lecturer,

Paediatric Surgery Institute of Child Health, Birmingham University, and Birmingham Children's Hospital, Birmingham, UK 
ASHISH DESAI

Surgical Registrar,

Birmingham Children's Hospital

1 CSM/MCA. Current Problems in Pharmacovigilance 1998;24.

2 Bernardini S, Semama DS, Huet F, Sgro C, Gouyon JB. Effects of cisapride on QTc interval in neonates. Arch Dis Child 1997;77:F241-3.

3 Schwartz PJ, Stramba-Badiale M, Segantini A, et al. Prolongation of the QT interval and the sudden infant death syndrome. $N$ Engl $f$ Med 1998;338:1709-14.

4 Valdes L, Champel V, Olivier C, Jonville-Bera AP, Autret E. Syncope with long QT interval in a 39 day-old infant treated with cisapride. Arch Pediatr 1997;4:535-7.

5 CSM/MCA. Current Problems in Pharmacovigilance 1996;22.

6 Hill SL, Evangelista JK, Pizzi AM, Mobassaleh M, Fulton DR, Berul CI. Proarrhythmia associated with cisapride in children. Pediatrics 1998;101: Proarrhy

7 Lupoglazoff JM, Bedu A, Faure C, et al. Long QT syndrome under cisapride in neonates and infants. Arch Pediatr 1997;4:509-14.

8 Levine A, Fogelman R, Sirota L, Zangen Z, Shamir R, Dinari G. QT interval in children and infants receiving cisapride. Pediatrics 1998;101:E9. (http://www.pediatrics.org)

9 Hedner T, Hedner J, Gelin-Friberg A, et al. Comparative bioavailability of a cisapride suppository and tablet formulation in healthy volunteers. Eur $\mathcal{F}$ Clin Pharmacol 1990;38:629-31.

10 Melis K, Janssens G. Long-term use of cisapride (Prepulsid) in premature neonates. Acta Gastroenterol Belg 1990;53:372-5.

11 Lander A, Redkar R, Nicholls G, et al. Cisapride reduces neonatal postoperative ileus: randomised placebo controlled trial. Arch Dis Child 1997;77: F119-22.

12 Vandenplas Y, Ashkenazi A, Belli D, et al. A proposition for the diagnosis and treatment of gastro-oesophageal reflux disease in children: a report from a working group on gastro-oesophageal reflux disease. Working Group of the European Society of Paediatric Gastroenterology and NutriGroup of the European Society of Paediatric Ga
tion (ESPGAN). Eur $\mathcal{7}$ Pediatr 1993;152:704-11.

13 Cucchiara S, Staiano A, Boccieri A, et al. Effects of cisapride on parameters of oesophageal motility and on the prolonged intraoesophageal $\mathrm{pH}$ test in infants with gastro-oesophageal reflux disease. Gut 1990;31:21-5.

14 Vandenplas Y, de Roy C, Sacre L. Cisapride decreases prolonged episodes of reflux in infants. F Pediatr Gastroenterol Nutr 1991;12:44-7.

15 Iacono G, Carroccio A, Montalto G, et al. Evaluation of the effectiveness of cisapride in the treatment of gastroesophageal reflux. Minerva Pediatr $1992 ; 44: 613-16$

16 Saye Z, Forget PP. Effect of cisapride on esophageal $\mathrm{pH}$ monitoring in children with reflux-associated bronchopulmonary disease. 7 Pediatr Gastroenterol Nutr 1989;8:327-32.
17 Malfroot A, Vandenplas Y, Verlinden M, Piepsz A, Dab I. Gastroesophageal reflux and unexplained chronic respiratory disease in infants and children. Pediatr Pulmonol 1987;3:208-13.

18 Saye ZN, Forget PP, Geubelle F. Effect of cisapride on gastroesophageal reflux in children with chronic bronchopulmonary disease: a double-blind cross-over pH-monitoring study. Pediatr Pulmonol 1987;3:8-12.

19 Van Eygen M, Van Ravensteyn H. Effect of cisapride on excessive regurgitation in infants. Clin Ther 1989;11:669-77.

20 Cucchiara S, Staiano A, Capozzi C, Di Lorenzo C, Boccieri A, Auricchio S. Cisapride for gastro-oesophageal reflux and peptic oesophagitis. Arch Dis Child 1987;62:454-7.

21 Rode H, Stunden RJ, Millar AJ, Cywes S. Esophageal pH assessment of gastroesophageal reflux in 18 patients and the effect of two prokinetic agents: cisapride and metoclopramide. F Pediatr Surg 1987;22:931-4.

22 Malfroot A, Dab I. New insights on gastro-oesophageal reflux in cystic fibrosis by longitudinal follow up. Arch Dis Child 1991;66:1339-45.

23 Dab I, Malfroot A. Gastroesophageal reflux: a primary defect in cystic fibrosis? Scand f Gastroenterol 1988;143(suppl):125-31.

24 Murray RD, Li BU, McClung HJ, Heitlinger L, Rehm D. Cisapride for intractable constipation in children: observations from an open trial. 7 Pediatr Gastroenterol Nutr 1990;11:503-8.

25 Nurko S, Garcia-Aranda JA, Guerrero VY, Worona LB. Treatment of intractable constipation in children: experience with cisapride. 7 Pediatr Gastroenterol Nutr 1996;22:38-44.

26 Staiano A, Cucchiara S, Andreotti MR, Minella R, Manzi G. Effect of cisapride on chronic idiopathic constipation in children. Dig Dis Sci 1991; 36:733-6.

27 Staiano A, Del Giudice E, Simeone D, Miele E, Marino A. Cisapride in neurologically impaired children with chronic constipation. Dig Dis Sci 1996;41:870-4.

28 Gil Vernet JM, Casasa JM, Boix Ochoa J, Salas A, Broto J, Marhuenda C. Intestinal dysmotility-pseudo-obstruction. Cir Pediatr 1992;5:87-95.

29 Hyman PE, Di Lorenzo C, McAdams L, Flores AF, Tomomasa T, Garvey TQ III. Predicting the clinical response to cisapride in children with chronic intestinal pseudo-obstruction. Am f Gastroenterol 1993;88:832-6.

30 Di Lorenzo C, Reddy SN, Villanueva-Meyer J, Mena I, Martin S, Hyman PE. Cisapride in children with chronic intestinal pseudoobstruction. An acute, double-blind, crossover, placebo-controlled trial. Gastroenterology 1991;101:1564-70.

31 Bindl L, Buderus S, Ramirez M, Kirchhoff P, Lentze MJ. Cisapride reduces postoperative gastrocaecal transit time after cardiac surgery in children. Intensive Care Med 1996;22:977-80.

\section{Varicella: to vaccinate or not to vaccinate?}

Despite the fact that live attenuated varicella vaccine was developed about 25 years ago, ${ }^{1}$ many questions remain about its use, the major, recurring one being whether it is worthwhile. Varicella is often perceived as a mild ailment. However, not only is varicella not necessarily a benign disease, but it is usually not possible to predict in advance whether an individual will develop a severe illness. In the United States, where varicella vaccine has been licensed for the past two years, utilisation rates vary across the country. The Centers for Disease Control and Prevention (CDC) has been alarmed by recent reports of deaths from varicella in healthy unvaccinated young women as well as in unvaccinated children. Currently in the United States, varicella is the leading cause of deaths that are preventable by vaccination. ${ }^{23}$

Complications of varicella include those described in this issue by Jaeggi and colleagues, ${ }^{4}$ and involve the central nervous system, bacterial superinfections, and severe infections in immunocompromised patients and adults. Although they concluded that the rate of complications in the population studied was low, one cannot assume that this will continue to be the case. For example, in the United States, invasive group A $\beta$ haemolytic streptococcal infections as a complication of varicella have been recognised as a mounting problem for less than a decade. ${ }^{5}$ Although these potentially life threatening bacterial superinfections are not now a problem in Switzerland, they might emerge in the future.

An additional illness that is not always perceived as a complication of varicella is zoster. Zoster occurs only in individuals who have previously had primary infection with varicella zoster virus (VZV), either as varicella or following vaccination; only these individuals may harbour latent VZV with the potential to reactivate and cause zoster. Importantly, it has now been demonstrated in two immunised populations, children with leukaemia ${ }^{6}$ and renal transplant patients, ${ }^{7}$ that zoster occurs five to seven times less frequently after vaccination than after natural varicella. It is possible that the decreased frequency of zoster in vaccinated people is either because of a lower rate of latent VZV infection after vaccination than after natural disease or a decreased ability of the vaccine virus to reactivate in dorsal root ganglia or both. Thus the goals of varicella immunisation are to prevent complications of VZV infection: encephalitis, ataxia, invasive group A streptococcal superinfections, varicella in immunocompromised children, pregnant women and other adults, and to prevent zoster. Only by widespread use of the vaccine can these goals be accomplished. Thus I take issue with Jaeggi et al, who propose immunisation only on a selective basis. This has been the approach in Japan, where only about $20 \%$ of children are immunised and there has been little impact of the vaccine on the population. ${ }^{8}$ Selective immunisation may also increase the incidence of varicella in adults, an occurrence that is highly undesirable. ${ }^{9}$

The duration of immunity is often cited as an unknown with regard to varicella vaccine. Following the introduction of any new vaccine, it is not possible to measure the duration of vaccine induced immunity until a lifetime has gone by. However, the record for varicella vaccine has been admirable. Small studies from Japan have indicated immunity persisting even after approximately 20 years. ${ }^{10}$ Recent studies from the United States indicate persistence of immunity in several hundred children for up to 10 years 
following immunisation. ${ }^{11}$ Additional studies on the duration of immunity are in progress.

Varicella vaccine seems to provide a lower degree of protection than some other live vaccines such as that against measles. In part, this may result from a greater scrutiny of varicella vaccine recipients in an age when seroconversions after vaccination have been evaluated, as well as from the stringent efficacy trials requiring the vaccine to prove effective even after intense household exposure to unvaccinated family members with full blown varicella. It appears that the rate of complete protection from varicella vaccine is about $90 \% .^{12}$ Risks for breakthrough varicella are described by Lim et al in this issue. ${ }^{13}$ These authors confirmed the importance of the immunising dose of this vaccine. Others have also found that the chance of developing a breakthrough infection is increased in people who manifest lower titres of antibodies in the weeks following immunisation, a phenomenon that is related directly to the titre of virus in the immunising dose. ${ }^{14}{ }^{15}$ The very best efficacy was shown in children who received a dose of vaccine about five times higher than that in currently licensed varicella vaccines. ${ }^{16}$ Therefore, better protection might be afforded by use of a higher titred varicella vaccine. VZV is notoriously difficult to propagate in vitro, so development of a higher titred vaccine that is economically feasible is a recognisably difficult task, but one worth pursuing.

Another risk factor for breakthrough varicella identified by $\operatorname{Lim}$ et al is immunisation at less than 1 year of age. ${ }^{13}$ This observation is in keeping with that of Terada et al who showed that the cell mediated immune response to VZV is age dependent. ${ }^{17}$ Young infants with varicella develop lower cell mediated immunity responses than older children. Thus, the recommendation to withhold varicella vaccination until after the first birthday, as is done in the United States, seems worthwhile. This recommendation may also be important, in that children who experience varicella either in utero or in the first year of life are at increased risk of developing zoster in the first few years of childhood. ${ }^{18}$

I believe that in developed countries we should aim to immunise all children over the age of 1 year, as well as adults who are susceptible to varicella, to control the disease and its complications. This approach may not be sensible in developing countries where more serious infec- tions such as measles and bacterial meningitis are not yet under control. However, there are arguments for the use of varicella vaccine in some developing regions where the incidence of varicella in adulthood is high, such as Southeast Asia. The physician must always remember the admonition of Hippocrates: "first do no harm". In consideration of varicella vaccine in developed countries, the benefits continue to outweigh the mainly theoretical risks. I believe the day has arrived when not immunising will cause more potential harm than immunisation.

Columbia University College of Physicians and Surgeons ANNE GERSHON 630 West 168th Street

New York, USA

Takahashi M, Otsuka T, Okuno Y, et al. Live vaccine used to prevent the spread of varicella in children in hospital. Lancet 1974;ii:1288-90.

2 Centers for Disease Control. Varicella-related deaths among adults, United States, 1997. MMWR Morb Mort Wkly Rep 1997;46:409-12.

Centers for Disease Control. Varicella-related deaths among children, United States, 1997. MMWR Morb Mort Wkly Rep 1998;47:365-8.

4 Jaeggi A, Zurbruegg RP, Aebi C. Complications of varicella in a defined central European population. Arch Dis Child 1998;79:472-7.

5 Davies HD, McGeer A, Schwarts B, et al. Invasive group A streptococcal infections in Ontario, Canada. N Engl F Med 1996;335:547-54.

6 Hardy I, Gershon AA, Steinberg SP, LaRussa P. The incidence of zoster after immunization with live attenuated varicella vaccine. A study in after immunization with live attenuated varicella vaccine

7 Broyer M, Tete MJ, Guest G, Gagnadoux MF, Rouzioux C. Varicella and zoster in children after kidney transplantation: long term results of vaccination. Pediatrics 1997;99:35-9.

8 Asano Y. Varicella vaccine: the Japanese experience. $\mathcal{F}$ Infect Dis 1996;174(suppl 3):S310-13.

9 Halloran ME. Epidemiologic effects of varicella vaccination. Infect Dis Clin North Am 1996;10:631-55.

10 Asano Y, Suga S, Yoshikawa T, et al. Experience and reason: twenty year follow up of protective immunity of the Oka live varicella vaccine. Pediatrics 1994;94:524-6.

11 Johnson CE, Stancin T, Fattlar D, Rome LP, Kumar ML. A long-term prospective study of varicella vaccine in healthy children. Pediatrics 1997;100: 761-6.

12 Gershon AA. Varicella-zoster virus: prospects for control. Adv Pediatr Infect Dis 1995;10: 93-124.

13 Lim YJ, Chew FT, Tan AYS, Lee BW. Risk factors for breakthrough varicella in healthy children. Arch Dis Child 1998;79:478-80.

14 White CJ. Clinical trials of varicella vaccine in healthy children. Infect Dis Clin North Am 1996;10:595-608.

15 Varis T, Vesikari T. Efficacy of high titer live attenuated varicella vaccine in healthy young children. F Infect Dis 1996;174(suppl 3):S330-4.

16 Weibel RE, Neff BJ, Kuter BJ, et al. Live attenuated varicella virus vaccine: efficacy trial in healthy children. N Engl f Med 1984;310:1409-15.

17 Terada K, Kawano S, Yoshihiro K, Morita T. Varicella-zoster virus (VZV) reactivation is related to the low response of $\mathrm{VZV}$-specific immunity after reactivation is related to the low response of VZV-spe
chickenpox in infancy. F Infect Dis 1994;169:650-2.

18 Dworsky M, Whitely R, Alford C. Herpes zoster in early infancy. Am J Dis Child 1980;134:618-19. 